\title{
Current Trends in Treatment of Status Epilepticus and Refractory Status Epilepticus
}

\author{
John P. Betjemann, MD ${ }^{1}$ \\ 1 Department of Neurology, University of California, \\ San Francisco, California \\ Semin Neurol 2015;35:621-628.
}

\begin{abstract}
Address for correspondence John Betjemann, MD, Department of Neurology, University of California, San Francisco General Hospital, 1001 Potrero Ave, Building 1, Room 101, San Francisco, CA 94110 (e-mail: John.Betjemann@ucsf.edu).
\end{abstract}

\begin{abstract}
Keywords

- seizures

- status epilepticus

- refractory status epilepticus

- epidemiology

- prehospital treatment

- diagnostic evaluation

Status epilepticus is a heterogeneous disorder with varied definitions and presentations. Taken together, all forms of status epilepticus carry significant morbidity and mortality, much of which is dictated by the underlying etiology. Generalized convulsive status epilepticus, which represents a common form, is a true neurologic emergency that requires emergent management. Treatment focuses on stabilizing the patient and aggressive medical management to achieve the timely termination of seizures. For other forms of status epilepticus including nonconvulsive and focal status epilepticus, the goal remains early seizure termination, but the use of intravenous medications should be weighed against the risks associated with these therapies. The diagnostic evaluation of status epilepticus is guided by the patient's history and should be broad, including a screen for toxins, electrolytes, structural abnormalities, and central nervous system infectious and autoimmune/inflammatory etiologies. Considerable research is still needed to improve our understanding of the mechanisms, consequences, and therapy of status epilepticus.
\end{abstract}

Status epilepticus (SE) represents a common neurologic emergency that if not treated appropriately and in a timely fashion can lead to significant neurologic injury and mortality. A heterogeneous disorder, SE is often organized into major categories, including generalized convulsive SE (GCSE), focal motor SE, nonconvulsive SE (NCSE), and refractory SE. The treatment of SE and outcomes are often dictated by which type of SE a patient is experiencing, the age of the patient, and the underlying etiology. Despite significant advances in research, practice patterns vary and controversy remains regarding the most appropriate treatment of the various forms of SE.

\section{Epidemiology and Prognosis}

When broadly defined as a seizure lasting more than 30 minutes or recurrent seizures with incomplete return to baseline, the annual incidence of SE ranges from 10 to 41 per 100,000 persons, or roughly 125,000 to 195,000 new cases annually in the United States. ${ }^{1-5}$ These figures may even be underestimates, particularly in the case of NCSE, which is only diagnosed through electroencephalographic (EEG) monitoring; recent studies of inpatient EEG monitoring, particularly in the intensive care unit (ICU), have demonstrated high rates of electrographic seizures that likely are underrecognized. ${ }^{6-11}$ Owing in part to this increase in SE detection in the hospital, the incidence of SE is increasing. ${ }^{12,13}$

Although greatly influenced by the etiology, overall mortality estimates related to SE approach $20 \%{ }^{1}$ and are not changing dramatically over time. ${ }^{12,13}$ When considering the causes of SE, it can be helpful to divide cases into acute and chronic etiologies. Acute symptomatic causes (i.e., stroke, metabolic, infectious, anoxic injury) tend to be more common than chronic causes (i.e., low antiepileptic drug level, alcohol abuse, tumor, remote effects from stroke) and are generally associated with a higher mortality. ${ }^{2,5,14}$ Given the increasing
Issue Theme Hospitalist Neurology; Guest Editors: S. Andrew Josephson, MD, and Vanja C. Douglas, MD ISSN $0271-8235$. 
incidence and associated morbidity and mortality, the costs of SE are substantial; direct inpatient costs related to SE are approximately $\$ 4$ billion annually in the United States. ${ }^{15}$

\section{Definitions of Status Epilepticus}

General agreement exists that SE should be treated promptly and effectively to minimize neuronal injury and overall morbidity and mortality. Although the majority of seizures self-terminate within 180 seconds, ${ }^{16}$ prolonged seizures become pharmacoresistant (especially to benzodiazepines) and are less likely to terminate spontaneously. ${ }^{17,18}$ Status epilepticus was previously defined as a seizure lasting more than 30 minutes based on studies of neuronal injury. ${ }^{19}$ However, the International League Against Epilepsy is considering a new operational definition advocating for the treatment of SE within 5 minutes of onset. Although this definition applies mainly to GCSE, in the future it may be extended to forms of focal motor SE and NCSE.

It is important to realize that the definitions of SE are continually changing and that significant overlap and limitations exist among the varied definitions. For this review, we will consider three main practical types of SE: GCSE, focal motor SE, and NCSE (-Table 1). Generalized convulsive SE and focal motor SE are characterized by overt rhythmic movements of the extremities and/or the face associated with an alteration in cognition. Nonconvulsive SE in adults is defined as prolonged epileptiform activity on EEG, though a generally accepted duration of epileptiform activity is not incorporated into the definition. There are many subdivisions of NCSE, which can be difficult to define, ${ }^{20}$ but for the purposes of this review we will focus on two main types: NCSE with coma, which is also commonly referred to as "subtle SE," and NCSE without coma. Nonconvulsive SE with coma often follows overt GCSE or acute severe brain injury and is characterized by a severe alteration in mental status and ongoing focal or generalized epileptiform discharges. Although there may be subtle twitching movements accompanying NCSE with coma, the diagnosis requires EEG. Nonconvulsive SE without coma implies a patient with epileptiform activity on EEG resulting in relatively mild alteration in cognition or behavior, sometimes referred to as the "wandering confused" patient. ${ }^{21}$ When considering the treatment of SE, particularly the urgency of treatment and escalation to anesthetics, a distinction is often made between GCSE and other forms of SE, with focal motor SE and the subtypes of NCSE often treated in a similar and somewhat less-aggressive fashion than GCSE.

A precise definition of refractory SE (RSE) is also lacking. A generally agreed-upon definition for RSE is any type of SE that persists despite adequate treatment with a first-line agent (benzodiazepines) and at least one second-line antiepileptic drug (AED). ${ }^{22}$ Refractory SE encompasses both convulsive and nonconvulsive SE; as in both, an EEG is often required to confirm the presence of ongoing seizure activity. Superrefractory SE (SRSE) is commonly defined as SE that persists for more than 24 hours after anesthetics have been introduced, and includes cases where SE was initially controlled by an anesthetic, but returns upon weaning the anesthetic.

\section{Treatment of Generalized Convulsive Status Epilepticus}

\section{Prehospital Treatment}

Recent research regarding the treatment of convulsive SE has focused on early identification and timely therapy in the prehospital setting in an effort to avoid ongoing pharmacoresistance and neuronal injury resulting from prolonged SE. The initial treatment of SE begins with the use of benzodiazepines following the results of the VA Cooperative Study, a randomized,

Table 1 Definitions of status epilepticus

\begin{tabular}{|c|c|}
\hline Type of SE & Definition \\
\hline Generalized convulsive & Overt generalized convulsive activity with altered cognition \\
\hline Focal motor & $\begin{array}{l}\text { Overt focal convulsive activity with altered cognition (previously complex } \\
\text { partial SE) }\end{array}$ \\
\hline Nonconvulsive & Prolonged focal or generalized electrographic seizure activity \\
\hline NCSE without coma & $\begin{array}{l}\text { Typically focal electrographic seizure activity resulting in altered cognition } \\
\text { described as the "wandering confused patient." Also referred to as dys- } \\
\text { cognitive focal SE }\end{array}$ \\
\hline NCSE with coma & $\begin{array}{l}\text { Also referred to as "subtle SE," often occurs following GCSE or an acute } \\
\text { severe brain injury and is characterized by focal or generalized electro- } \\
\text { graphic seizure activity and severely altered cognition (i.e., coma) }\end{array}$ \\
\hline Refractory & $\begin{array}{l}\text { SE that persists despite appropriate treatment with benzodiazepines and a } \\
\text { second-line AED }\end{array}$ \\
\hline Superrefractory & $\begin{array}{l}\text { SE persisting for more than } 24 \text { hours after the introduction of anesthetics } \\
\text { including SE that was initially controlled by an anesthetic but returns upon } \\
\text { weaning the medication. }\end{array}$ \\
\hline
\end{tabular}

Abbreviations: AED, antiepileptic drug; NCSE, nonconvulsive status epilepticus; SE, status epilepticus. 
double-blind comparison of four intravenous (IV) treatments: lorazepam, phenytoin, phenobarbital, or diazepam plus phenytoin. ${ }^{23}$ Status epilepticus was terminated in $65 \%$ of patients treated with lorazepam, similar to the results seen with phenobarbital and diazepam plus phenytoin and superior to the phenytoin monotherapy arm. Intravenous lorazepam has therefore served as the initial medication of choice for SE.

Two randomized, double-blind trials examined the efficacy and safety of benzodiazepines administered by paramedics in the prehospital setting. The first compared IV diazepam (5-10 mg), IV lorazepam (2-4 mg), and placebo, and found that patients who received either lorazepam or diazepam were more likely to have their SE terminated upon arrival to the emergency room than patients receiving placebo. ${ }^{24}$ In addition, those receiving a benzodiazepine were less likely to experience respiratory compromise. The more recent Rapid Anticonvulsant Medication Prior to Arrival Trial (RAMPART) compared IV lorazepam ( $4 \mathrm{mg}$ in adults, $2 \mathrm{mg}$ in children) to intramuscular (IM) midazolam (10 mg in adults, $5 \mathrm{mg}$ in children) and concluded that IM midazolam was at least as safe and effective for terminating SE in the prehospital setting. ${ }^{25}$ Based on the findings of these pivotal trials, the first-line treatment of SE begins with either IV lorazepam or IM midazolam prior to arrival in the emergency room.

Numerous studies have also examined the efficacy of benzodiazepine abortive medications to be administered by patients and caregivers for acute repetitive seizures and SE (-Table 2). Early studies demonstrated the efficacy of rectal diazepam, but more recently, the development of buccal and IM preparations of midazolam have allowed for easier and more socially acceptable routes of administration.

\section{Hospital Management}

The initial management of a patient in GCSE begins with vital sign stabilization and airway management. Although the initial treatment of SE begins with the use of benzodiazepines ( - Fig. 1), significant practice variability exists in the treatment of SE refractory to adequate benzodiazepines alone. Second-line AEDs that have been investigated include IV phenytoin, fosphenytoin, valproic acid, phenobarbital, levetiracetam, and lacosamide. Convention in the United States leans toward the use of phenytoin or fosphenytoin. Although fosphenytoin is more costly, it offers the advantages of a lower risk for adverse reactions related to IV extravasation and can be administered at a faster rate than phenytoin with no increased risk of arrhythmias or hypotension. ${ }^{26}$ Dosing for phenytoin and fosphenytoin is weight-based $(20 \mathrm{mg} / \mathrm{kg})$. A second smaller dose of 5 to $10 \mathrm{mg} / \mathrm{kg}$ can be administered if the patient is still suspected to be seizing. Common practice is to aim for a slightly supratherapeutic corrected phenytoin level $(20-30 \mu \mathrm{g} / \mathrm{ml})$, though further escalation of treatment should not be delayed for laboratory results if the patient continues to seize.

Numerous studies have attempted to compare these secondline agents, but small sample sizes and methodological variability limit their interpretation and applicability. It is important to note that no class I data exist comparing the efficacy of these second-line AEDs. A recent meta-analysis of the most commonly used second-line AEDs found that valproic acid was most efficacious, stopping SE in $75.7 \%$ of patients, followed by phenobarbital $73.6 \%$, levetiracetam $68.5 \%$, and phenytoin $50.2 \%$; lacosamide had insufficient evidence to analyze. ${ }^{27}$ The authors advise caution when interpreting the data, noting several limitations including the relatively small number of studies comparing these AEDs, a preponderance of observational studies, and heterogeneous methodologies. A Cochrane review summarizing studies comparing these second-line AEDs concluded that the results are uncertain and further study is needed. ${ }^{28}$ These findings underscore the importance of the Established Status Epilepticus Treatment Trial (ESETT; NCT01960075). Funded by the National Institute of Neurologic Disorders and Stroke, ESETT

Table 2 Selected studies of abortive medications for seizures and status epilepticus

\begin{tabular}{|c|c|c|c|c|}
\hline Study & Population and setting & $N$ and AEDs & Methodology & Conclusions \\
\hline Knudsen, $1979^{67}$ & $\begin{array}{l}\text { Children in ED } \\
\text { and inpatient }\end{array}$ & 59 rDZP & prospective & $\begin{array}{l}\text { rDZP was effective } \\
\text { in aborting } \\
\text { seizures in } 80 \% \text { of cases }\end{array}$ \\
\hline Scott et al, $1999^{68}$ & $\begin{array}{l}\text { Outpatient adolescents; } \\
\text { seizure lasting }>5 \mathrm{~min}\end{array}$ & 40 bMDZ vs. 39 rDZP & $\begin{array}{l}\text { Prospective, } \\
\text { randomized }\end{array}$ & $\begin{array}{l}\text { bMDZ is at least } \\
\text { as effective } \\
\text { and safe as rDZP }\end{array}$ \\
\hline Lahat et al, $2000^{69}$ & $\begin{array}{l}\text { Children in ED; } \\
\text { febrile seizure } \\
>10 \text { min }\end{array}$ & 21 inMDZ vs. 23 ivDZP & $\begin{array}{l}\text { Prospective, } \\
\text { randomized }\end{array}$ & $\begin{array}{l}\text { inMDZ is as safe and } \\
\text { effective as ivDZP }\end{array}$ \\
\hline Cerehino et al, $2002^{70}$ & $\begin{array}{l}\text { Outpatient adults } \\
\text { with acute } \\
\text { repetitive seizures }\end{array}$ & 42 rDZP vs. 54 placebo & $\begin{array}{l}\text { Multicenter, } \\
\text { prospective, } \\
\text { randomized, } \\
\text { double-blind } \\
\text { placebo controlled }\end{array}$ & $\begin{array}{l}\text { rDZP was effective } \\
\text { in reducing } \\
\text { likelihood of acute } \\
\text { repetitive seizures }\end{array}$ \\
\hline Mclntyre et al, $2005^{71}$ & Children in ED & 109 bMDZ vs. 110 rDZP & $\begin{array}{l}\text { Prospective, } \\
\text { randomized }\end{array}$ & $\begin{array}{l}\text { bMDZ was more } \\
\text { effective } \\
\text { than rDZP and } \\
\text { was as safe. }\end{array}$ \\
\hline
\end{tabular}

Abbreviations: AEDs, antiepileptic drugs; bMDZ, buccal midazolam; ED, emergency department; inMDZ, intranasal midazolam; ivDZP, intravenous diazepam; rDZP, rectal diazepam. 


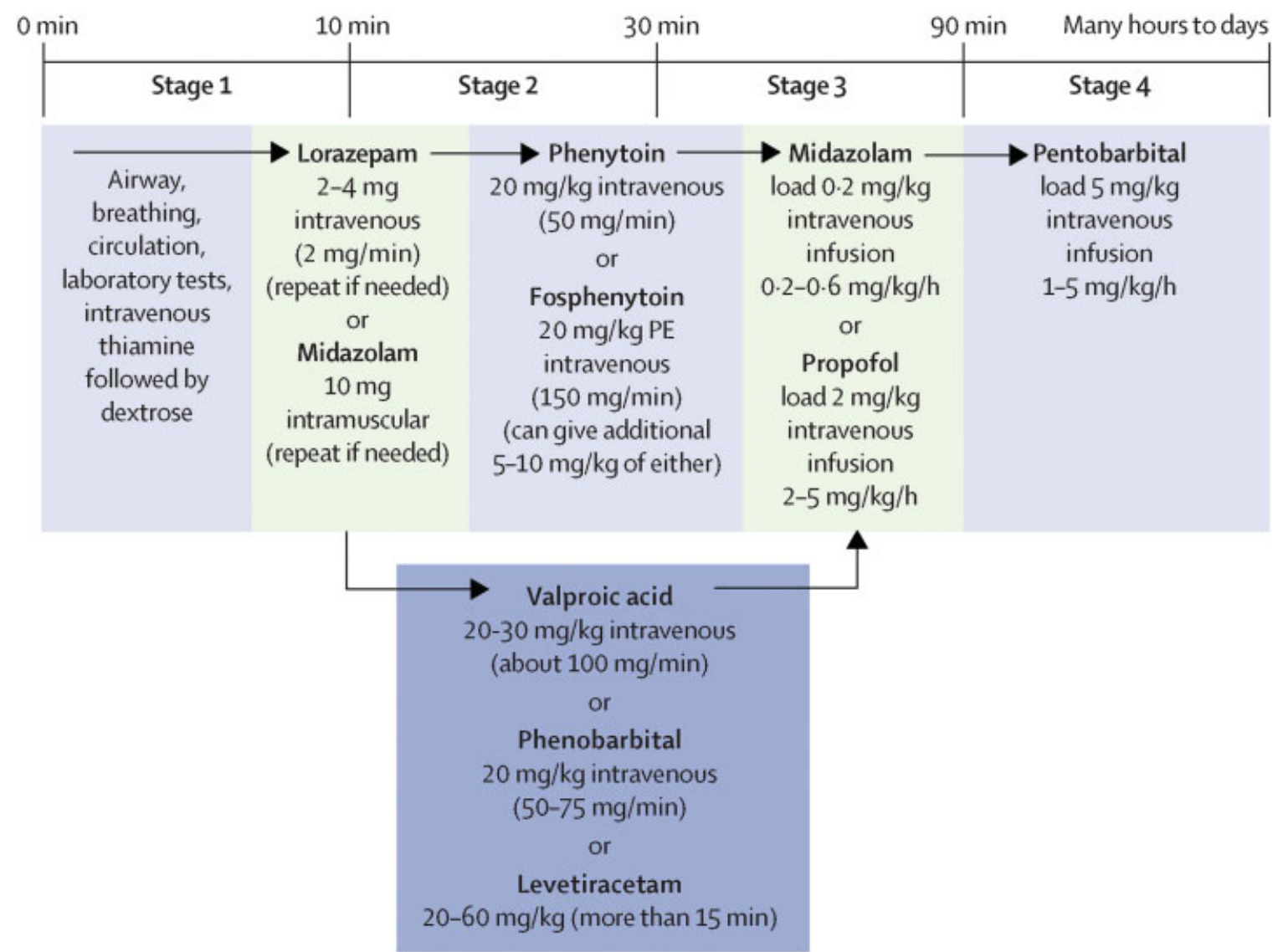

Fig. 1 Generalized convulsive status epilepticus treatment algorithm. ABCs, airway, breathing, circulation; IV, intravenous. (Reprinted with permission from Betjemann JP, Lowenstein DH. Status epilepticus in adults. Lancet Neurol 2015;14:615).

is to begin enrollment in late 2015 and will compare fosphenytoin, valproic acid, and levetiracetam in a blinded, randomized fashion for the treatment of SE refractory to benzodiazepines. ${ }^{29}$

When SE is refractory to benzodiazepines and a second-line $\mathrm{AED}$, a decision must be made regarding the next step in treatment. Prior convention may have included another trial of a second-line AED, but more recent practice patterns indicate a shift toward early anesthetic use in adults with refractory GCSE. $^{30}$ Although no absolute consensus exists, the updated treatment algorithm presented in - Fig. 1 advocates for early escalation (within 30-60 minutes of seizure onset) to an anesthetic agent such as propofol or midazolam rather than another trial of a second-line AED. The rationale behind this recommendation is based on evidence of systemic and neuronal injury from continued GCSE, as well as the development of pharmacoresistance to medications with prolonged seizures. The decision to use an anesthetic agent must be weighed against its potentially serious complications.

\section{Treatment of Focal Motor Status Epilepticus and Nonconvulsive Status Epilepticus}

A relative lack of data exists to guide the management of focal motor SE and NCSE. Often their treatment strategy is similar, as these forms of SE are felt to be less of a true medical emergency because they lack the generalized convulsive activity that can result in severe metabolic dysfunction; however, some evidence exists demonstrating that even NCSE can result in neuronal injury, questioning this less time-pressured approach. ${ }^{31,32}$ In the VA Cooperative Study, subtle SE was terminated in only 8 to $24 \%$ of cases, with no significant difference found between treatment arms of lorazepam alone, diazepam plus phenytoin, phenytoin alone, and phenobarbital alone. ${ }^{23}$

The treatment of focal motor SE and forms of NCSE still focuses on timely management and early seizure cessation, and begins with one or two rounds of benzodiazepines according to the GCSE treatment algorithm. Similarly, if seizures persist, a second-line AED is the next step in management. When focal motor SE or NCSE is refractory to first- and second-line treatments, consideration should be given to scheduled benzodiazepines and additional AED trials prior to escalating to intubation and IV anesthetics, particularly in cases of SE when consciousness is relatively preserved. ${ }^{33}$ Phenytoin/fosphenytoin, valproic acid, levetiracetam, and phenobarbital can all be considered as potential adjunct second-line therapies. Intravenous lacosamide $^{34-36}$ and oral topiramate ${ }^{37-39}$ have also been suggested for refractory SE.

If multiple trials of AEDs are unsuccessful over the course of a few days, anesthetics should be more strongly 
considered, taking into account the risks of infection and cardiovascular compromise. In cases of GCSE evolving into NCSE with coma or "subtle SE," some experts advocate for early escalation to anesthetics similar to the approach for GCSE. The varied practice patterns employed in the treatment of SE in its different forms is highlighted by the results of surveys among experts in the field. ${ }^{30,40,41}$

\section{Refractory Status Epilepticus and Superrefractory Status Epilepticus}

Refractory SE (RSE) is defined as SE that persists despite an appropriately dosed first-line agent (benzodiazepines) and a second-line AED; superrefractory SE (SRSE) refers to SE that persists for more than 24 hours following the introduction of anesthetics. A study of patients appropriately treated for convulsive SE found that $48 \%$ went on to have continued nonconvulsive seizures and $15 \%$ were diagnosed with NCSE, underscoring the importance of continuous EEG to identify RSE and guide its treatment. ${ }^{42}$

Although data are limited, more recent studies estimate that 23 to $43 \%$ of patients in SE will progress to RSE, and the mortality of RSE ranges from 17 to $39 \%{ }^{22,43-46}$ Similar to nonrefractory SE, mortality is largely dependent on the underlying etiology for RSE and the patient's age. Refractory SE tends to be more commonly associated with acute severe brain injuries such as ischemic stroke and CNS infection, and less likely to be associated with more "benign" etiologies such as chronic epilepsy and low AED levels. $^{43,44}$ Patients in RSE are less likely to return to baseline, have significantly longer hospital stays, and are significantly more likely to require inpatient rehabilitation than are patients who experience nonrefractory SE. ${ }^{44}$ In addition, patients who survive RSE are more likely develop symptomatic epilepsy following SE compared with those who experience nonrefractory SE. ${ }^{43}$

The treatment of RSE and SRSE centers around rapid seizure control to minimize systemic and neurologic compromise while balancing the risks associated with prolonged intubation and anesthetics. A concurrent, extensive diagnostic investigation should be undertaken to identify potentially reversible causes such as metabolic, infectious, or inflammatory etiologies. Detailed reviews of the treatment of RSE and SRSE are provided elsewhere. ${ }^{47,48}$ Propofol, midazolam, and thiopental are commonly used first-line anesthetics for RSE, with pentobarbital often being reserved for use as a second-line anesthetic for those patients still refractory after these initial medications. All of these medications should be given as an initial bolus followed by a maintenance infusion to assure adequate serum levels of the drugs. A systematic review comparing pentobarbital, midazolam, and propofol found no significant difference in overall mortality, and noted that treatment with pentobarbital was associated with fewer breakthrough seizures, but was also associated with an increased risk of hypotension. ${ }^{49}$ Propofol has been associated with a life-threatening infusion syndrome, particularly during prolonged infusions and in children. Midazolam has been associated with tachyphylaxis, often necessitating frequent dosage adjustments. Both propofol and midazolam have relatively short half-lives, as opposed to pentobarbital, which is advantageous when frequent neurologic exams need to be performed. In the absence of randomized data to guide management decisions, selection of an anesthetic should be individualized and based on factors including comorbidities, cardiovascular status, drug interactions, and institutional experience.

When treating RSE with an anesthetic, continuous EEG is needed to help guide therapy. The goal is to achieve electrographic seizure suppression and potentially a burst-suppression EEG pattern. No definitive data exist to determine what adequate burst-suppression entails and how long it should be maintained. Convention is to aim for 1 to 2 seconds of cerebral activity with 10 -second interburst intervals of background suppression for a total of 24 to 48 hours before attempting to lighten sedation. This period of electrographic suppression also provides an opportunity to add on maintenance AEDs and quickly bring them to therapeutic levels before weaning sedation.

In cases where seizures return upon lightening sedation (SRSE), further therapeutic pharmacological options can be considered, though data are extremely limited. Case reports suggest the efficacy of IV ketamine infusion even in cases where traditional GABAergic anesthetics fail. ${ }^{50-52}$ Ketamine has theoretical advantages, including its potential to be neuroprotective via modulation of N-methyl-D-aspartate (NMDA) activity and its lack of cardiovascular side effects. ${ }^{48}$ A multicenter retrospective study concluded that ketamine infusion was safe and potentially efficacious when administered via a loading dose followed by a continuous infusion..$^{53}$ The inhaled anesthetics isoflurane and desflurane have been discussed in case reports, but should be used with caution given their potential for serious adverse events including hypotension, atelectasis, infections, and ileus. ${ }^{54}$ Reports, especially in the pediatric literature, have also suggested IV lidocaine as being potentially efficacious. ${ }^{55-57}$ Magnesium can control seizures related to eclampsia, and more recently in cases of mitochondrial encephalopathy and RSE related to a POLG1 mutation. ${ }^{58}$ Similarly, IV pyridoxine has a role in patients with an inborn error in metabolism of pyridoxine, but should be also considered in other patients owing to its low-risk profile. ${ }^{59}$

There are numerous reports, primarily in children, of successfully using the ketogenic diet in aborting RSE. ${ }^{60-62}$ The diet is relatively easy to administer via nasogastric tube, but does require interdisciplinary teamwork with a nutritionist. The diet is contraindicated in patients with pyruvate carboxylase and $\beta$-oxidation deficiencies, and is probably best avoided when patients are receiving concurrent propofol or steroids.

Recently, immunologic therapy including steroids, IV immunoglobulin, and plasma exchange has gained enthusiasm for the treatment of new-onset RSE (NORSE) in light of increased appreciation for immunomediated causes of SE, including anti-NMDA receptor encephalitis and voltage-gated potassium antibody-mediated encephalitis. It is important to attempt to rule out infections and perform a thorough diagnostic workup prior to initiating immune therapy, as treatment can impact the ability to make an alternative diagnosis. 
There are also several nonpharmacologic options for SRSE, including electroconvulsive therapy (ECT) and surgery. A few published reports have suggested that ECT typically administered in 1 to 6 sessions over nearly consecutive days can terminate SRSE. ${ }^{63,64}$ Electroconvulsive therapy requires an experienced multidisciplinary team and also requires continuous EEG monitoring to ensure that the patient experiences an induced seizure during the treatment. There are numerous surgical options including focal resective surgery, vagal nerve stimulator placement, multiple subpial transection, and corpus callosotomy. Surgical approaches require a highly specialized multidisciplinary team who can develop a surgical plan, and in the case of resective surgery, requires evidence of a focal epileptogenic focus.

\section{Diagnostic Evaluation of a Patient in Status Epilepticus}

The initial diagnostic evaluation of a patient in SE should be occurring in conjunction with treatment and should not delay emergent therapy (-Table 3 ). The evaluation begins with a careful history aimed at identifying potential etiologies, including a prior history of seizures and medication noncompliance, which remains the single most common etiology of
SE. ${ }^{14}$ The history should also focus on new medications, illicit substances, and recent or remote injuries that may have triggered SE. An urgent laboratory evaluation should focus on reversible etiologies, including signs of infection, metabolic disturbances, renal and liver failure, toxin ingestion, and low AED levels. In most instances, AED levels for phenytoin, carbamazepine, valproic acid, and phenobarbital can be obtained relatively quickly, but most other AED levels will take days to result. Brain imaging should be obtained once convulsions are controlled. Practically, this often begins with a contrasted computed tomography (CT) scan of the head, but if an explanation is not elucidated, an MRI should be performed once the patient is stabilized. Status epilepticus is a clinical diagnosis that does not require an EEG; importantly, treatment should not be delayed to obtain one.

Electroencephalography becomes increasingly important in instances where a patient remains persistently altered, raising concern for ongoing electrographic seizures, and when titrating medications to treat a patient with RSE. A lumbar puncture is an important early test in patients with human immunodeficiency virus/acquired immunodeficiency syndrome (HIV/AIDS) and when suspicion exists for a lifethreatening infection such as bacterial meningitis or herpes simplex virus encephalitis. Treatment with AEDs, antibiotics,

Table 3 Diagnostic evaluation for status epilepticus

\begin{tabular}{|c|c|}
\hline Diagnostic test & Importance \\
\hline Detailed history & Known epilepsy and poor AED compliance \\
\hline Medications & Examples: bupropion, $\beta$-lactams, clozapine, isoniazid, theophylline \\
\hline Illicit drugs & Stimulants: cocaine, methamphetamine \\
\hline Withdrawal & Alcohol, benzodiazepines, barbiturates \\
\hline Brain injury & Stroke, infection, tumor, traumatic brain injury \\
\hline \multicolumn{2}{|l|}{ Screening labs } \\
\hline $\mathrm{CBC}$ & Leukocytosis suggesting infection \\
\hline CMP & $\begin{array}{l}\text { Hyponatremia, hypocalcemia, hypercalcemia, hypomagnesemia, hyper-/ } \\
\text { hypoglycemia, renal failure, liver failure }\end{array}$ \\
\hline AED levels & Phenytoin, valproic acid, carbamazepine, phenobarbital \\
\hline Urine toxicology & Evidence of illicit substances \\
\hline $\begin{array}{l}\text { Imaging } \\
\text { Contrasted CT } \\
\text { MRI }\end{array}$ & $\begin{array}{l}\text { Evidence of obvious structural abnormalities } \\
\text { Preferred method for identifying numerous abnormalities including } \\
\text { encephalitis, abscess, ischemic stroke and tumor }\end{array}$ \\
\hline EEG & $\begin{array}{l}\text { Not a necessary initial step but should be obtained for patients with persistent } \\
\text { altered mental status following SE or to titrate anesthetics for burst } \\
\text { suppression }\end{array}$ \\
\hline CSF & $\begin{array}{l}\text { Should be done early if suspicion exists for bacterial meningitis or HSV } \\
\text { encephalitis. For persistently unexplained SE, CSF testing should include } \\
\text { screening for atypical infections and evidence of inflammation (oligoclonal } \\
\text { bands and IgG index) }\end{array}$ \\
\hline $\begin{array}{l}\text { Secondary } \\
\text { laboratories }\end{array}$ & $\begin{array}{l}\text { HIV, autoimmune/inflammatory etiologies including thyroid antibodies, } \\
\text { serum/CSF paraneoplastic panel }\end{array}$ \\
\hline
\end{tabular}

Abbreviations: AED, antiepileptic drug; CBC, complete blood count; CMP, comprehensive metabolic panel; CSF, cerebrospinal fluid; CT, computed tomography; EEG, electroencephalography; HIV, human immunodeficiency virus; HSV, herpes simplex virus; MRI, magnetic resonance imaging; SE, status epilepticus. 
and acyclovir should not be delayed to obtain cerebrospinal fluid.

If no cause for SE is identified during the initial evaluation, a more thorough workup can be entertained. This should include a careful search for causes of immunosuppression including HIV, as well as further cerebrospinal fluid testing for atypical bacterial, viral, fungal, and protozoal infections that are extensively reviewed elsewhere. ${ }^{65,66}$ A constellation of symptoms including seizures, ophthalmoplegia, ataxia, and myoclonus in a child or young adult should prompt consideration of a genetic defect, particularly a mitochondrial disorder. Recently, immune disorders have been increasingly recognized as the cause of previously unexplained cases of new-onset SE, and often RSE. It is extremely important to identify these syndromes as the treatment of SE involves immunotherapy in addition to AEDs. Two of the more commonly described autoimmune syndromes leading to SE are anti-NMDA receptor encephalitis and voltage-gated potassium channel antibody autoimmunity, though numerous other autoantibodies can cause SE. ${ }^{66}$ When SE remains unexplained, serum thyroperoxidase antibodies and antithyroglobulin antibodies as well as serum and CSF paraneoplastic antibody screens should be considered, especially in the setting of an unexplained lymphocytic pleocytosis in the spinal fluid or other signs of CSF inflammation such as an elevated IgG index or unique oligoclonal bands. If an autoantibody is identified, systemic imaging to look for an occult malignancy should be undertaken, as many paraneoplastic syndromes will respond best to treatment of the underlying malignancy.

\section{Conclusion}

Although SE is a relatively common neurologic disorder with significant morbidity and mortality, many management questions remain. Further research should focus on the most appropriate algorithm for the treatment of SE. Additional studies are also needed to examine the utility and cost effectiveness of EEG monitoring to identify SE in hospitalized patients and its impact on outcomes. Finally, continued efforts to identify the myriad causes of SE, particularly novel autoimmune/inflammatory etiologies, are critical as their successful treatment often depends on prompt identification and treatment.

\section{References}

1 DeLorenzo RJ, Hauser WA, Towne AR, et al. A prospective, population-based epidemiologic study of status epilepticus in Richmond, Virginia. Neurology 1996;46(4):1029-1035

2 Hesdorffer DC, Logroscino G, Cascino G, Annegers JF, Hauser WA. Incidence of status epilepticus in Rochester, Minnesota, 19651984. Neurology 1998;50(3):735-741

3 Logroscino G, Hesdorffer DC, Cascino G, Annegers JF, Hauser WA. Time trends in incidence, mortality, and case-fatality after first episode of status epilepticus. Epilepsia 2001;42(8):1031-1035

4 Knake S, Rosenow F, Vescovi M, et al; Status Epilepticus Study Group Hessen (SESGH). Incidence of status epilepticus in adults in Germany: a prospective, population-based study. Epilepsia 2001; 42(6):714-718

5 Coeytaux A, Jallon P, Galobardes B, Morabia A. Incidence of status epilepticus in French-speaking Switzerland: (EPISTAR). Neurology 2000;55(5):693-697
6 Towne AR, Waterhouse EJ, Boggs JG, et al. Prevalence of nonconvulsive status epilepticus in comatose patients. Neurology 2000;54(2):340-345

7 Claassen J, Mayer SA, Kowalski RG, Emerson RG, Hirsch LJ. Detection of electrographic seizures with continuous EEG monitoring in critically ill patients. Neurology 2004;62(10):1743-1748

8 Oddo M, Carrera E, Claassen J, Mayer SA, Hirsch LJ. Continuous electroencephalography in the medical intensive care unit. Crit Care Med 2009;37(6):2051-2056

9 Kamel H, Betjemann JP, Navi BB, et al. Diagnostic yield of electroencephalography in the medical and surgical intensive care unit. Neurocrit Care 2013;19(3):336-341

10 Betjemann JP, Nguyen I, Santos-Sanchez C, Douglas VC, Josephson SA. Diagnostic yield of electroencephalography in a general inpatient population. Mayo Clin Proc 2013;88(4):326-331

11 Kurtz P, Gaspard N, Wahl AS, et al. Continuous electroencephalography in a surgical intensive care unit. Intensive Care Med 2014; 40(2):228-234

12 Dham BS, Hunter K, Rincon F. The epidemiology of status epilepticus in the United States. Neurocrit Care 2014;20(3):476-483

13 Betjemann JP, Josephson SA, Lowenstein DH, Burke JF. Trends in status epilepticus-related hospitalizations and mortality: redefined in US practice over time. JAMA Neurol 2015;72(6):650-655

14 DeLorenzo RJ, Pellock JM, Towne AR, Boggs JG. Epidemiology of status epilepticus. J Clin Neurophysiol 1995;12(4):316-325

15 Penberthy LT, Towne A, Garnett LK, Perlin JB, DeLorenzo RJ. Estimating the economic burden of status epilepticus to the health care system. Seizure 2005;14(1):46-51

16 Jenssen S, Gracely EJ, Sperling MR. How long do most seizures last? A systematic comparison of seizures recorded in the epilepsy monitoring unit. Epilepsia 2006;47(9):1499-1503

17 Kapur J, Macdonald RL. Rapid seizure-induced reduction of benzodiazepine and Zn2 + sensitivity of hippocampal dentate granule cell GABAA receptors. J Neurosci 1997;17(19):7532-7540

18 Jones DM, Esmaeil N, Maren S, Macdonald RL. Characterization of pharmacoresistance to benzodiazepines in the rat Li-pilocarpine model of status epilepticus. Epilepsy Res 2002;50(3):301-312

19 Treatment of convulsive status epilepticus. Recommendations of the Epilepsy Foundation of America's Working Group on Status Epilepticus. JAMA 1993;270(7):854-859

20 Shorvon $S$. What is nonconvulsive status epilepticus, and what are its subtypes? Epilepsia 2007;48(Suppl 8):35-38

21 Brophy GM, Bell R, Claassen J, et al; Neurocritical Care Society Status Epilepticus Guideline Writing Committee. Guidelines for the evaluation and management of status epilepticus. Neurocrit Care 2012;17(1):3-23

22 Mayer SA, Claassen J, Lokin J, Mendelsohn F, Dennis LJ, Fitzsimmons B-F. Refractory status epilepticus: frequency, risk factors, and impact on outcome. Arch Neurol 2002;59(2):205-210

23 Treiman DM, Meyers PD, Walton NY, et al. A comparison of four treatments for generalized convulsive status epilepticus. Veterans Affairs Status Epilepticus Cooperative Study Group. N Engl J Med 1998;339(12):792-798

24 Alldredge BK, Gelb AM, Isaacs SM, et al. A comparison of lorazepam, diazepam, and placebo for the treatment of out-of-hospital status epilepticus. N Engl J Med 2001;345(9):631-637

25 Silbergleit R, Durkalski V, Lowenstein D, et al; NETT Investigators. Intramuscular versus intravenous therapy for prehospital status epilepticus. N Engl J Med 2012;366(7):591-600

26 Browne TR, Kugler AR, Eldon MA. Pharmacology and pharmacokinetics of fosphenytoin. Neurology 1996;46(6, Suppl 1):S3-S7

27 Yasiry Z, Shorvon SD. The relative effectiveness of five antiepileptic drugs in treatment of benzodiazepine-resistant convulsive status epilepticus: a meta-analysis of published studies. Seizure 2014; 23(3):167-174

28 Prasad M, Krishnan PR, Sequeira R, Al-Roomi K. Anticonvulsant therapy for status epilepticus. Cochrane Database Syst Rev 2014;9: CD003723 
29 Cock HR; ESETT Group. Established status epilepticus treatment trial (ESETT). Epilepsia 2011;52(Suppl 8):50-52

30 Riviello JJ Jr, Claassen J, LaRoche SM, et al; Neurocritical Care Society Status Epilepticus Guideline Writing Committee. Treatment of status epilepticus: an international survey of experts. Neurocrit Care 2013;18(2):193-200

31 Meldrum BS, Vigouroux RA, Brierley JB. Systemic factors and epileptic brain damage. Prolonged seizures in paralyzed, artificially ventilated baboons. Arch Neurol 1973;29(2):82-87

32 Rabinowicz AL, Correale JD, Bracht KA, Smith TD, DeGiorgio CM. Neuron-specific enolase is increased after nonconvulsive status epilepticus. Epilepsia 1995;36(5):475-479

33 Meierkord H, Boon P, Engelsen B, et al; European Federation of Neurological Societies. EFNS guideline on the management of status epilepticus in adults. Eur J Neurol 2010;17(3):348-355

34 Legros B, Depondt C, Levy-Nogueira M, et al. Intravenous lacosamide in refractory seizure clusters and status epilepticus: comparison of 200 and $400 \mathrm{mg}$ loading doses. Neurocrit Care 2014; 20(3):484-488

35 Koubeissi MZ, Mayor CL, Estephan B, Rashid S, Azar NJ. Efficacy and safety of intravenous lacosamide in refractory nonconvulsive status epilepticus. Acta Neurol Scand 2011;123(2):142-146

36 Rantsch K, Walter U, Wittstock M, Benecke R, Rösche J. Efficacy of intravenous lacosamide in refractory nonconvulsive status epilepticus and simple partial status epilepticus. Seizure 2011;20(7): 529-532

37 Hottinger A, Sutter R, Marsch S, Rüegg S. Topiramate as an adjunctive treatment in patients with refractory status epilepticus: an observational cohort study. CNS Drugs 2012;26(9): 761-772

38 Stojanova V, Rossetti AO. Oral topiramate as an add-on treatment for refractory status epilepticus. Acta Neurol Scand 2012;125(2):e7-e11

39 Towne AR, Garnett LK, Waterhouse EJ, Morton LD, DeLorenzo RJ The use of topiramate in refractory status epilepticus. Neurology 2003;60(2):332-334

40 Claassen J, Hirsch LJ, Mayer SA. Treatment of status epilepticus: a survey of neurologists. J Neurol Sci 2003;211(1-2):37-41

41 Holtkamp M, Masuhr F, Harms L, Einhäupl KM, Meierkord H, Buchheim K. The management of refractory generalised convulsive and complex partial status epilepticus in three European countries: a survey among epileptologists and critical care neurologists. J Neurol Neurosurg Psychiatry 2003;74(8):1095-1099

42 DeLorenzo RJ, Waterhouse EJ, Towne AR, et al. Persistent nonconvulsive status epilepticus after the control of convulsive status epilepticus. Epilepsia 1998;39(8):833-840

43 Holtkamp M, Othman J, Buchheim K, Meierkord H. Predictors and prognosis of refractory status epilepticus treated in a neurological intensive care unit. J Neurol Neurosurg Psychiatry 2005;76(4): 534-539

44 Novy J, Logroscino G, Rossetti AO. Refractory status epilepticus: a prospective observational study. Epilepsia 2010;51(2):251-256

45 Rossetti AO, Logroscino G, Bromfield EB. Refractory status epilepticus: effect of treatment aggressiveness on prognosis. Arch Neurol 2005;62(11):1698-1702

46 Hocker SE, Britton JW, Mandrekar JN, Wijdicks EF, Rabinstein AA. Predictors of outcome in refractory status epilepticus. JAMA Neurol 2013;70(1):72-77

47 Rossetti AO, Lowenstein DH. Management of refractory status epilepticus in adults: still more questions than answers. Lancet Neurol 2011;10(10):922-930

48 Shorvon S, Ferlisi M. The treatment of super-refractory status epilepticus: a critical review of available therapies and a clinical treatment protocol. Brain 2011;134(Pt 10):2802-2818

49 Claassen J, Hirsch LJ, Emerson RG, Mayer SA. Treatment of refractory status epilepticus with pentobarbital, propofol, or midazolam: a systematic review. Epilepsia 2002;43(2):146-153

50 Prüss H, Holtkamp M. Ketamine successfully terminates malignant status epilepticus. Epilepsy Res 2008;82(2-3):219-222
51 Esaian D, Joset D, Lazarovits C, Dugan PC, Fridman D. Ketamine continuous infusion for refractory status epilepticus in a patient with anticonvulsant hypersensitivity syndrome. Ann Pharmacother 2013;47(11):1569-1576

52 Hsieh CY, Sung PS, Tsai JJ, Huang CW. Terminating prolonged refractory status epilepticus using ketamine. Clin Neuropharmacol 2010;33(3):165-167

53 Gaspard N, Foreman B, Judd LM, et al. Intravenous ketamine for the treatment of refractory status epilepticus: a retrospective multicenter study. Epilepsia 2013;54(8):1498-1503

54 Mirsattari SM, Sharpe MD, Young GB. Treatment of refractory status epilepticus with inhalational anesthetic agents isoflurane and desflurane. Arch Neurol 2004;61(8):1254-1259

55 Walker IA, Slovis CM. Lidocaine in the treatment of status epilepticus. Acad Emerg Med 1997;4(9):918-922

56 Hamano S, Sugiyama N, Yamashita S, et al. Intravenous lidocaine for status epilepticus during childhood. Dev Med Child Neurol 2006;48(3):220-222

57 Hattori H, Yamano T, Hayashi K, et al. Effectiveness of lidocaine infusion for status epilepticus in childhood: a retrospective multiinstitutional study in Japan. Brain Dev 2008;30(8):504-512

58 Visser NA, Braun KP, Leijten FS, van Nieuwenhuizen O, Wokke JH, van den Bergh WM. Magnesium treatment for patients with refractory status epilepticus due to POLG1-mutations. J Neurol 2011;258(2):218-222

59 Ferlisi M, Shorvon S. The outcome of therapies in refractory and super-refractory convulsive status epilepticus and recommendations for therapy. Brain 2012;135(Pt 8):2314-2328

60 Bodenant M, Moreau C, Sejourné C, et al. [Interest of the ketogenic diet in a refractory status epilepticus in adults]. Rev Neurol (Paris) 2008;164(2):194-199

61 Caraballo RH, Flesler S, Armeno M, et al. Ketogenic diet in pediatric patients with refractory focal status epilepticus. Epilepsy Res 2014;108(10):1912-1916

62 Cobo NH, Sankar R, Murata KK, Sewak SL, Kezele MA, Matsumoto $\mathrm{JH}$. The ketogenic diet as broad-spectrum treatment for superrefractory pediatric status epilepticus: challenges in implementation in the pediatric and neonatal intensive care units. J Child Neurol 2015;30(2):259-266

63 Kamel H, Cornes SB, Hegde M, Hall SE, Josephson SA. Electroconvulsive therapy for refractory status epilepticus: a case series. Neurocrit Care 2010;12(2):204-210

64 Shin HW, O'Donovan CA, Boggs JG, et al. Successful ECT treatment for medically refractory nonconvulsive status epilepticus in pediatric patient. Seizure 2011;20(5):433-436

65 Tan RY, Neligan A, Shorvon SD. The uncommon causes of status epilepticus: a systematic review. Epilepsy Res 2010;91(2-3): 111-122

66 Lowenstein DH, Walker M, Waterhouse E. Status epilepticus in the setting of acute encephalitis. Epilepsy Curr 2014;14(1, Suppl): 43-49

67 Knudsen FU. Rectal administration of diazepam in solution in the acute treatment of convulsions in infants and children. Arch Dis Child 1979;54(11):855-857

68 Scott RC, Besag FM, Neville BG. Buccal midazolam and rectal diazepam for treatment of prolonged seizures in childhood and adolescence: a randomised trial. Lancet 1999;353(9153):623-626

69 Lahat E, Goldman M, Barr J, Bistritzer T, Berkovitch M. Comparison of intranasal midazolam with intravenous diazepam for treating febrile seizures in children: prospective randomised study. BMJ 2000;321(7253):83-86

70 Cereghino JJ, Cloyd JC, Kuzniecky RI; North American Diastat Study Group. Rectal diazepam gel for treatment of acute repetitive seizures in adults. Arch Neurol 2002;59(12):1915-1920

71 McIntyre J, Robertson S, Norris E, et al. Safety and efficacy of buccal midazolam versus rectal diazepam for emergency treatment of seizures in children: a randomised controlled trial. Lancet 2005; 366(9481):205-210 